\title{
Effect of Artificial Aging Temperature on Mechanical Properties and Micro Structure of Al-Mg-Si Composite
}

\author{
Yono Hadi Pramono a) and Affandy Subyanto \\ Department of Physics, Faculty of Mathematics and Science, Institut Teknologi Sepuluh Nopember (ITS), Surabaya \\ 60111 Indonesia \\ a)Corresponding author: yonohadipramono@gmail.com
}

\begin{abstract}
Temperature determination used in artificial aging process will affect hardness after quenching process and mechanical properties of Al-Mg-Si composite. Thus, the aim of this research is determining temperature used in aging process to obtain mechanical properties optimum. It was done by the procedures as follows: initially, solution heat treatment of Al-Mg-Si composite was set at $400^{\circ} \mathrm{C}$ then quenching process on water medium followed by aging treatment at various temperatures $\left(130^{\circ} \mathrm{C}, 180^{\circ} \mathrm{C}, 230^{\circ} \mathrm{C}, 280^{\circ} \mathrm{C}\right.$ and $\left.330^{\circ} \mathrm{C}\right)$ for 1.5 hours of HT. After the process, products were analyzed by hardness test to observe the micro-structure change of the samples. The result shows that hardness value of material increased with temperature process $\left(130-280^{\circ} \mathrm{C}\right)$ about $10 \%$. The hardness value rises from $48.05 \mathrm{HV}$ before artificial aging to $53.13 \mathrm{HV}$.
\end{abstract}

Keywords: artificial aging, mechanical properties, micro structure, heat treatment, and quenching

\section{INTRODUCTION}

Aluminium and its alloys are important material due to the high technological value and wide applications. Aluminum has a low density $(2.69 \mathrm{~g} / \mathrm{cm} 3)$ so that this material used widely in the automotive industries. The low density of aluminium can reduce the overall weight of the vehicle more than $300 \mathrm{~kg}$ for medium sized vehicles (1400 kg). It will reduce fuel consumption up to 0.3-0.6 liters per $100 \mathrm{~km}$ in every $100 \mathrm{~kg}$ of reduction weight. Thus, it reduces the gas emission up to $20 \%$.

Aluminum is also used widely in the manufacturing industries. It is caused by the mechanical properties of aluminium can be mixed with other elements (alloys) forming a composites (MMCs) to arrange characteristics such as mechanical properties, castability, machineabillity, surface finish, corrosion resistance, heat and electrical conductivity, weldability, and hot tear resistance. The adding of magnesium on aluminum cause lower material weight and increasing impact resistance (Surdia \& Saito, 1992). The material of Al-Mg composite is isolator material before adding other elements (such as $\mathrm{Si}$ ) into Al-Mg composite. This element can change the composite properties from isolator to be conductor material.

The previous research shows that the material of Al-Mg-Si composite has a poor characteristic in hardness properties. To improve the composite properties, it can be done by artificial aging process (i.e. re-heating the composite material after quenching process at certain temperature and time). This process was done to form sediment or fine particles in the matrix so that it increased the strength and hardness of the material. In this research, the correlation between the aging temperature to the mechanical properties and microstructure of Al-Mg-Si composite will be studied by powder metallurgy method. 


\section{LITERATURE REVIEW}

\section{Composite Material}

Composite material consists of two or more different materials which have surface bonding on the material. The composite strength depends on the surface bonding strength of matrix to strengthener. This bonding is the external transmission bridge from the matrix into the reinforcing particles. The composite material has been developed as an alternative material to obtain better properties such as high strength / modulus and low density. Continuous strenghteners have better specific strength properties however high strength fibres and its manufacturing methods are more expensive than other composites. Recently, the industries develop new types of composites like composites with discontinuous reinforcement. This composite has poorer properties than other but lower cost needed, and easier methods. Moreover, the composite with discontinuous reinforcement has isotropic properties, i.e the same properties in all directions (transverse and longitudinal directions). Instead anisotropic composite is composites which its strengthener give unequal reinforcement to different directions.

\section{Characteristic of Metal Matrix Composite}

Metal matrix composites (MMCs) consist of the metal matrix and its alloys reinforced by strengthener material as continuous fibre, whisker, or particulate. The properties of this composite depend on several factors such as the composite material used, fraction of the reinforcement volume, dimension and shape of the strengthener and several other process variables. Matrix material commonly used are aluminum and its alloys which have physical and mechanical characteristics in Table 1 (Smith \& Hashemi, 2006).

TABLE 1. Mechanical properties and physical properties of aluminum metal

\begin{tabular}{l|c}
\hline \multicolumn{2}{c}{ Physical Properties } \\
\hline Density, $\rho$ & $2,69 \mathrm{~g} / \mathrm{cm} 3$ \\
Crystal structure & FCC \\
Melting point & $660^{\circ} \mathrm{C}$ \\
\hline \multicolumn{2}{c}{ Mechanical Properties } \\
\hline Modulus young & $71 \mathrm{Gpa}$ \\
Shear modulus & $26 \mathrm{Gpa}$ \\
Hardness & $19 \mathrm{VHN}$ \\
Yield strength, $\sigma \neg \mathrm{Y}$ & $25 \mathrm{Mpa}$ \\
Thermal conductifity, C & $237 \mathrm{~W} / \mathrm{mK}$ \\
\hline
\end{tabular}

\section{Powder metallurgy}

Powder metallurgy is to study about powders, product of powders after pressurising process followed by sintering process under melting temperatures. Steps of powder metallurgy techniques include several processes such as preparation, mixing, compression, and heating (sintering). Preparation step aims to select the materials of composite based on mechanical and physical properties of the composite. The next step is mixing process done correctly which is divided into 2 methods: wet mixing and dry mixing method. After mixing process, the composite will be processed by compaction process to form powder into the desired shape. One of the process is uniaxial pressing process (by pressing the powder using punch in a mold) to produce a green compact product with a certain strength (green strength) and density (green density). The last step to make composite is heating process. Initially, the composite is heated at $1 / 3$ of melting point, called presintering process, continued by sintering process which heated at $2 / 3$ of melting point. There are two main phenomena during sintering process; shrinkage (porcity) and grain growth. Sintering process have many parameters such as temperature, time, speed of heating and cooling, and also the sintering atmosphere (as external air, inert gas and vacuum) (Callister, 2007).

Mechanical properties of Aluminum both in powder metallurgy and cast product can be improved by heat treatment or cooling process to get the required mechanical properties. The main purposes of heat treatment process on aluminum are:

1. Soften the alloy to get easier process (not relevant for casting process).

2. To increase the strength and obtain the desired mechanical properties. 
3. To stabilize physical or mechanical properties or corrosion resistance, and to avoid properties change with time at room temperature or higher temperature.

4. To ensure dimensional stability during usage.

5. To remove residual stress caused by uneven cooling.

\section{Test of composite material}

Composite material test is done by X-ray Diffraction (XRD), metallographic, and mechanical test. The XRD test basically consists of an X-ray source, a sample and a detector. X-ray diffractometers are one of tools that can identify chemical compounds in the sample by quantitative and qualitative analysis as a benchmark. XRD is processed by a crystal to determine the characteristics of the material and its chemical compounds based on Bragg's law. Phases in the sample can determine by comparing it with material phases in ASTM or by comparing it with diffraction patterns of standard known powder. Metallography is a method to observe metal structures using optical microscopes and electron microscopes. Microstructure photo has enlargement 100-1000 times for optical microscope and 5000-30.000 times for electron microscope.

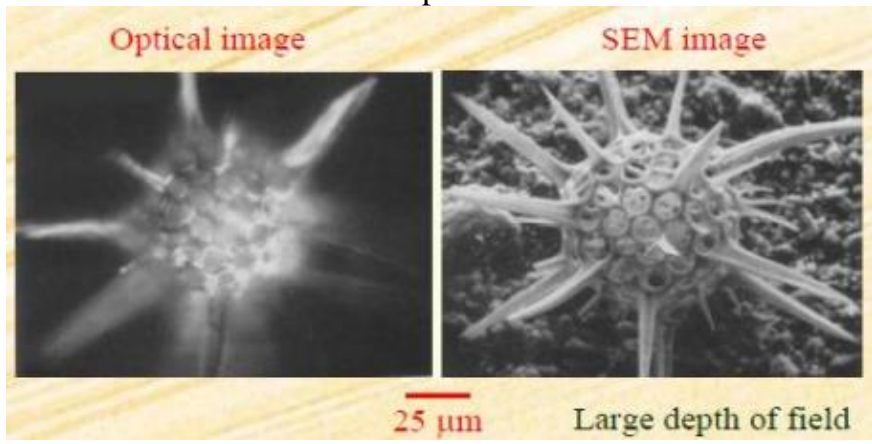

FIGURE 1. Morphological changes of sample

Hardness is one of the mechanical properties of a material. The hardness of a material must be known especially for material with frictional force and plastic deformation usage. Plastic deformation is a state of material when the material is given force then the microstructure of the material can not return into its original shape. Hardness can also be analyzed by Vickers macro hardness test method. The Vickers hardness test uses a diamond pyramid pellet with angle of the opposite surface of pyramid is $136^{\circ}$. Vickers hardness can be obtained by dividing forces on the extent of pyramidal shapes after pressurizing process (Smallman \& Bishop, 2000).

\section{METHODS}

\section{Research Flowchart}

This study was done using flowchat below:

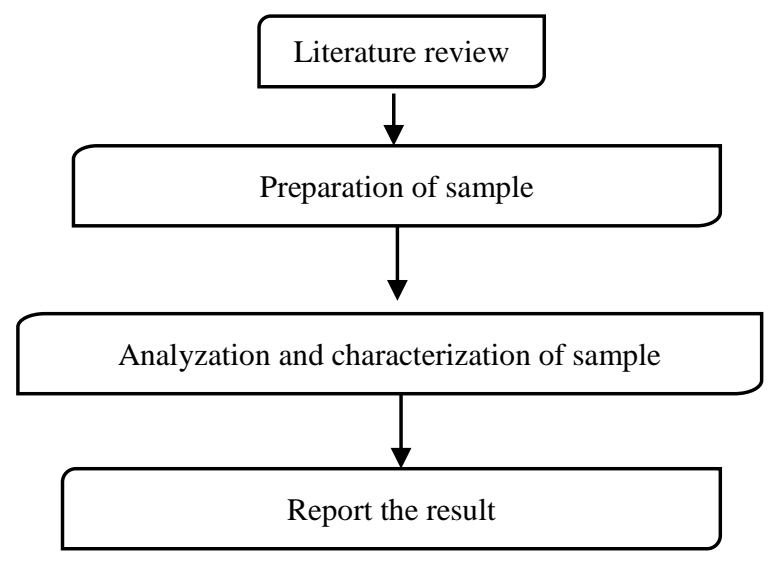

FIGURE 2. Flowchart of Methods 


\section{Literature review}

The aim of literature review is to study related previous research used as a basis for determination of variable, data analysis and discussion in the next research. The literature used in this research include textbooks, scientific articles and journals from internet.

\section{Prepation of sample}

This study used three powder materials such as aluminum, magnesium and silicon. Aluminum is used as a matrix whereas magnesium and silicon as filler (amplifier). The steps of sample preparation consist of preparation, mixing, pellet making, sintering and aging.

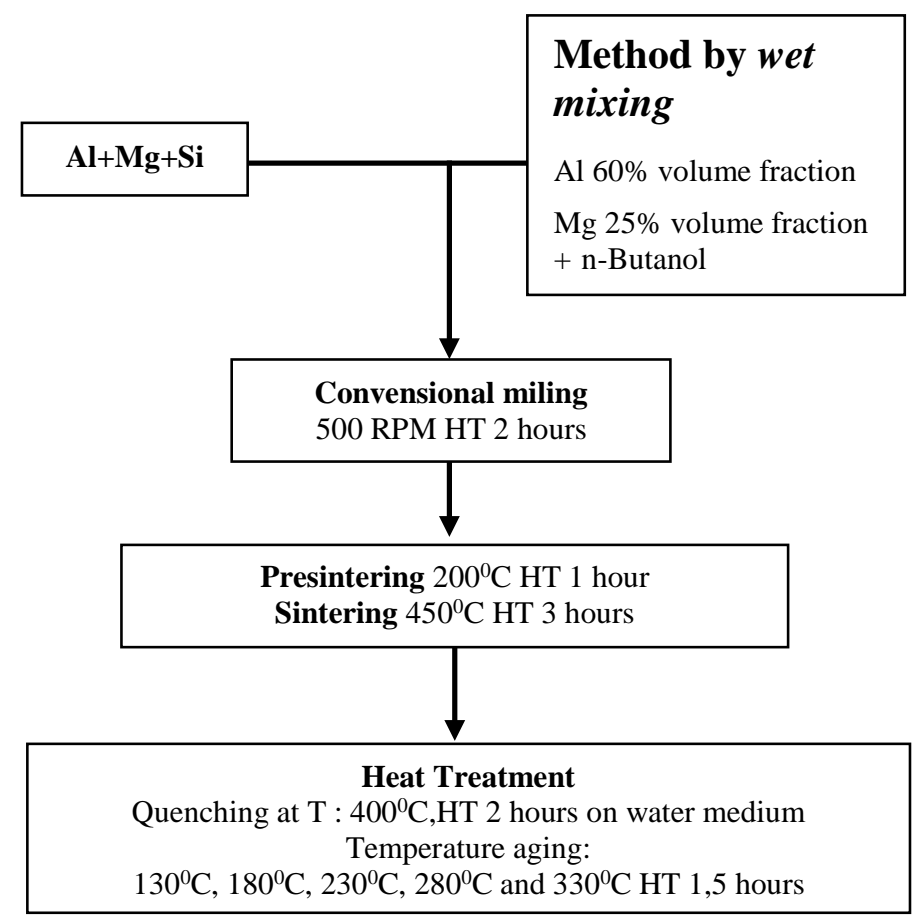

FIGURE 3. Flowchart of Sample Preparation

\section{Preparation Process}

The aims of preparation process is to make sample from Al-Mg-Si composite material by the volume fraction ratio of $\mathrm{Al} \mathrm{60 \% ,} \mathrm{Mg} 25 \%$, Si $15 \%$.

\section{Mixing Process}

Mixing process was done to mix aluminum, magnesium and silicon metal powders homogeneously. The mixing process of the powders with given volume fractions respectively was stirred by n-butanol solution (wet mixing) as a mixing medium in a miling process for 2 hours at $500 \mathrm{rpm}$. After the mixing process, it was heated (in the oven) to evaporate / remove the entire liquid n-butanol.

\section{Pressurizing Process}

The pressurizing process was done to compress the sample to be compact material. A homogenized $\mathrm{Al}, \mathrm{Mg}, \mathrm{Si}$ metal powder mixture is inserted in a cylindrical mold then pressed it with 3 tons of cold pressing for 15 minutes. 


\section{Presintering and Sintering Process}

After the sample formed, the process was continued by presentering + sintering process. This process is used to increase bonding strength of grains. Firstly, compacted sample was heated by presintering process at $200^{\circ} \mathrm{C}$ for 1 hour. The presintering process is to remove the internal stress and the remaining gases during mixing and compacting process. The process was continued by sintering at $450^{\circ} \mathrm{C}$ for 3 hours under furnace condition.

\section{Aging Process}

After the sintering process, the sample was treated by aging process. Initially, the sample was heated at $400^{\circ} \mathrm{C}$ for 2 hours then quenched it on water medium and continued by reheating at various temperature process $\left(130^{\circ} \mathrm{C}\right.$, $180^{\circ} \mathrm{C}, 230^{\circ} \mathrm{C}, 280^{\circ} \mathrm{C}$ and $330^{\circ} \mathrm{C}$ ) while the sample was heated for 1.5 hours at given temperature.

\section{Analization and Characterization of sample}

The analyzation and characterization of samples were done by 4 methods; Photo optical microscope, macrohardness Vickers, XRD, SEM and EDS test at PT BIN BATAN. The first step of preperation before characterization is polishing the sample to facilitate the observation by X-ray Diffraction (XRD) test. XRD test was done using X-ray diffractometer. The measurement was done from $15^{\circ}$ up to $80^{\circ}$ of $2 \theta$ with $0.04^{\circ}$ of increment. This test is to determine the phase formed in Al-Mg-Si composites during process and the possibility of undesirable impurities. Hardness test was done by using Vickers macrohardness, with wolpert probat tool. SEM + EDS test was done by the same sample used in micro photo test. This test has higher accuracy and can show the chemical composition of samples.

\section{RESULTS AND DISCUSSION}

Hardness test in this research was done by using Vickers macro hardness method to determine the ability of a material to resist penetration and indentation. This test was done at 3 points to determine the hardness distribution of Al-Mg-Si composite material. The hardness values of composite material are Aluminum 35 HV, Magnesium 26.42 $\mathrm{HV}$ and Silicon $87 \mathrm{HV}$ respectively. The results of hardness test by Vickers macro hardness on aging temperature $\left(130^{\circ} \mathrm{C}, 180^{\circ} \mathrm{C}, 230^{\circ} \mathrm{C}, 280^{\circ} \mathrm{C}\right.$ and $\left.330^{\circ} \mathrm{C}\right)$ for 1.5 hours of HT on the Al-Mg-Si composite are shown in Figure 4. Metallographic test with 100x magnification can indicate change of micro structure due to heat treatment, such as hardness.

Microstructure is described as a grain arrangement on the metal surface. On each grain, all unit cells are ordered by particular direction and pattern. Each granules have differences over the direction of crystal orientation that called as grain boundary area. There are any factors that affect micro structure such as chemical composition, processing and heat treatment. Figure 5 shows the sample structure change after compaction until aging process. It was caused by necking process and porosity removal after heat treatment process so that the mechanical properties of material increased. 


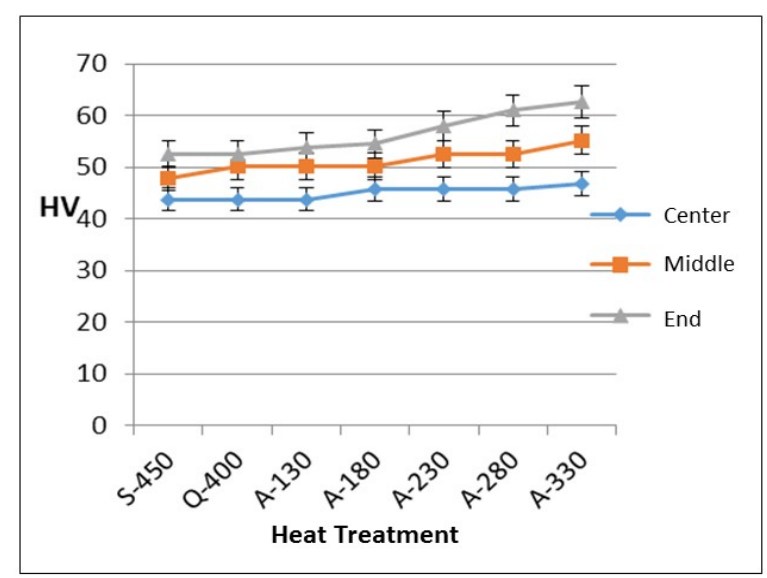

FIGURE 4. Effect of Temperature on Hardness

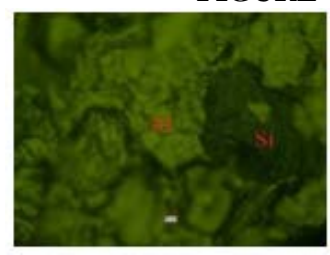

(a)

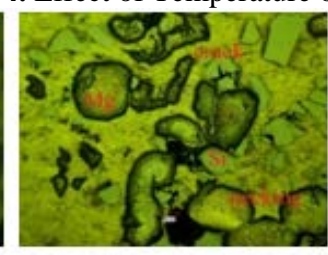

(b)

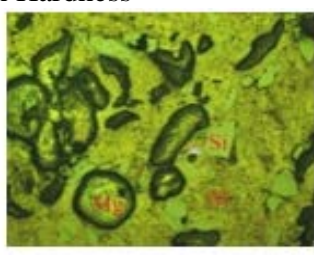

(c)

FIGURE 5. Micrography of Al-Mg-Si Composite; (a).after compression process;

(b). after quenching process; and (c). after aging process.

After processing, the sample was analyzed by X-ray diffraction (XRD) test to identify material phase qualitatively and quantitatively. In this test, the composition of Al:Mg:Si (Aluminium : Magnesium : Silicone) powder has to be equal at different temperature to determine the appropriate temperature for aging process. The main process of XRD test is when X-rays fall on the crystal lattice then the same phase rays will be diffracted to amplify the inner rays but the different phase rays will be negated each other. Theoretically, crystal structure of substance can determine diffraction pattern of substance. Shape and unit cell size of substance can determine angle and diffraction line. Atoms arrangement of substance in the unit cell determines relative intensity of lines in the substance. Thus diffraction intensity is determined by position of unit cell atoms. The position of atom is expressed by the hkl plane. The possibility of unfractionated Bragg's angle is due to the unequal hkl plane so that the angle is also different. Crystalline structure characteristic of the composite by X-rays shows a pattern on the powder sample. Identification result of Al-Mg-Si composite (metal phase) shows that the sample has peak orientation as shown PCDFWIN data.

The result of XRD test shows that there is three phases in the sample (aluminum, magnesium, and silicon phase). In this research, the sample didn't form metal oxide phase because of wet mixing process with polar solvent which can minimize the oxide formed during the mixing process and also using cold compaction method.

Based on diffraction pattern of the composite, there was less oxide formed ( $<5 \%$ of the sample) so that no diffraction peak of oxide. However, the result of EDS test showed a existence of oxides. The oxide was formed due to reaction of metal with oxygen. Temperature process of the sample could accelerate oxidation process.

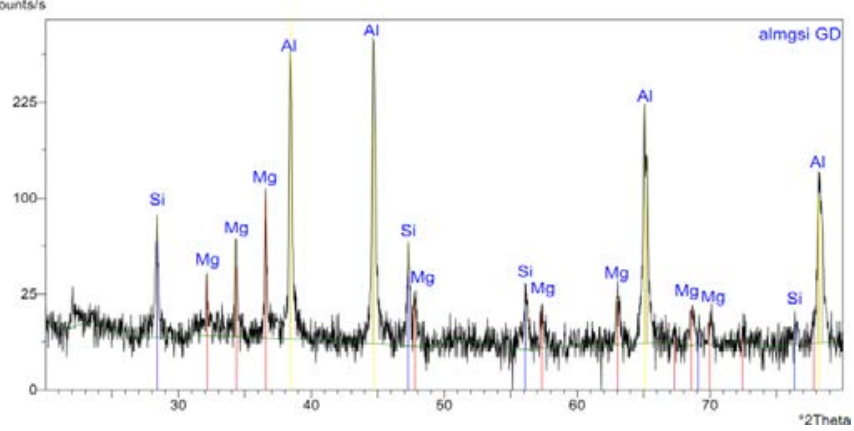

(a) 


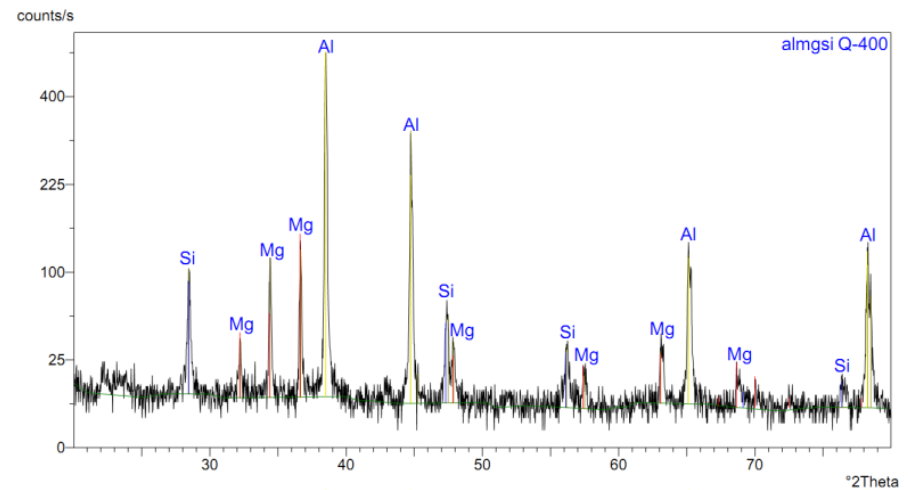

(b)

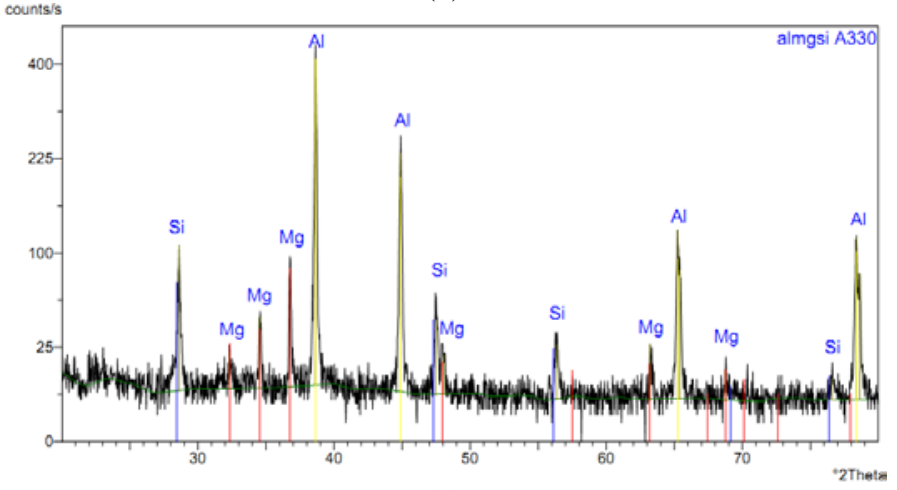

(c)

FIGURE 6. XRD Pattern of Al-Mg-Si Composite: (a).after compression process; (b). after quenching process; and (c). after aging process.

Figure 6 (a), (b), and (c) shows the same diffraction pattern but the different intensity. It is caused the different heat treatment on the sample so that the diffraction quantity on crystal plane is different. The intensity decreases with increasing temperature then the number of particles is more. Increasing aging temperatures extend the freedom of atoms to obtain greater distribution so there will be the same oriented plane to reinforce each other when it crush on the sample. This condition caused the intensity of sample is higher than after quenching process because of thermal change. The quenching process occurs at an extreme condition in a thermal change so that the atoms of sample don't arrange thoroughly then there is an arrangement of atoms and the internal elimination of stress in the aging process.
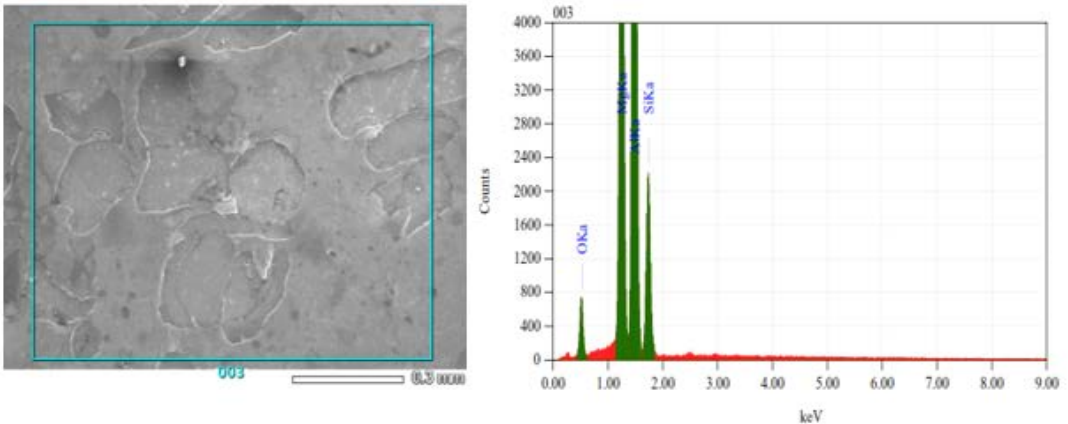

ZAF Method Standardless Quantitative Analysis

Fitting Coefficient : 0.2397

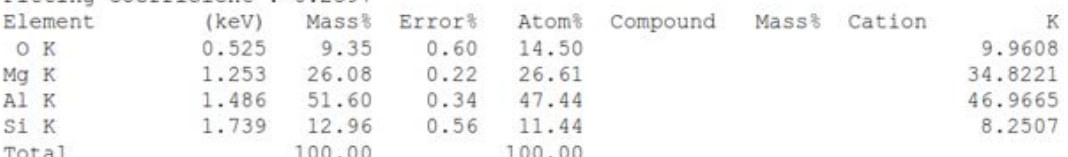

FIGURE 7. SEM+EDS Data of Al-Mg-Si Composite after Quenching Process 
In this research, the Al-Mg-Si composite consists of aluminum as matrix and magnesium and silicon as filler with volume fraction of $\mathrm{Al} 60 \%$, Mg 25\%, Si $15 \%$. Figure 7 shows that the mass percentage of sample approached to characterization values and also the filler distributed to the matrix. The data of EDS test also confirm that the oxide formed in the samples is $9 \%$ of the total material.

\section{CONCLUSSION}

The conclusion of this study are:

1. Aging temperature increased with hardness value of Al-Mg-Si composite. Maximum hardness value occurred in the upper ends of the sample region due to the largest strengthener distribution in this region.

2. Hardness value in aging process is $60.2 \mathrm{HV}$ than $52.45 \mathrm{HV}$ of the initial hardness value and the optimum aging temperature occured at $1800-280^{\circ} \mathrm{C}$.

3. No precipitate formed causes the temperature of solution treatment (preheating in quenching process) is lower than the temperature of precipitate hardening so that there was no new phase formed in the composite product.

\section{REFERENCES}

Callister, W. D. (2007). Materials Science and Engineering. New York: John Wiley \& Sons, Inc.

Smallman, R. E., \& Bishop, R. J. (2000). Metalurgi fisik modern dan rekayasa material. Jakarta: Erlangga.

Smith, W. F., \& Hashemi, J. (2006). Foundations of materials science and engineering (4th edition.). New York: McGraw-Hill.

Surdia, T., \& Saito, S. (1992). Pengetahuan bahan teknik. Jakarta: Pradnya Paramita. 